\title{
Altered microglial response to $A \beta$ plaques in APPPS1-21 mice heterozygous for TREM2
}

\author{
Jason D Ulrich ${ }^{1}$, Mary Beth Finn ${ }^{1}$, Yaming Wang ${ }^{2}$, Alice Shen ${ }^{1}$, Thomas E Mahan ${ }^{1}$, Hong Jiang ${ }^{1}$, Floy R Stewart ${ }^{1}$, \\ Laura Piccio ${ }^{1}$, Marco Colonna ${ }^{2,3}$ and David M Holtzman ${ }^{1,4,5,6^{*}}$
}

\begin{abstract}
Background: Recent genome-wide association studies linked variants in TREM2 to a strong increase in the odds of developing Alzheimer's disease. The mechanism by which TREM2 influences the susceptibility to Alzheimer's disease is currently unknown. TREM2 is expressed by microglia and is thought to regulate phagocytic and inflammatory microglial responses to brain pathology. Given that a single allele of variant TREM2, likely resulting in a loss of function, conferred an increased risk of developing Alzheimer's disease, we tested whether loss of one functional trem2 allele would affect A $\beta$ plaque deposition or the microglial response to A $\beta$ pathology in APPPS1-21 mice.

Results: There was no significant difference in A $\beta$ deposition in 3-month old or 7-month old APPPS1-21 mice expressing one or two copies of trem2. However, 3-month old mice with one copy of trem2 exhibited a marked decrease in the number and size of plaque-associated microglia. While there were no statistically significant differences in cytokine levels or markers of microglial activation in 3- or 7-month old animals, there were trends towards decreased expression of NOS2, C1qa, and IL1a in 3-month old TREM2 ${ }^{+/-} \mathrm{Vs}^{\text {. }} \mathrm{TREM}^{+/+}$mice.

Conclusions: Loss of a single copy of trem 2 had no effect on A $\beta$ pathology, but altered the morphological phenotype of plaque-associated microglia. These data suggest that TREM2 is important for the microglial response to $A \beta$ deposition but that a $50 \%$ decrease inTREM2 expression does not affect $A \beta$ plaque burden.
\end{abstract}

Keywords: Alzheimer's disease, TREM2, Microglia, Amyloid $\beta$

\section{Background}

One of the hallmarks of Alzheimer's disease (AD) is the extracellular deposition of amyloid- $\beta(A \beta)$ peptide in the brain parenchyma as amyloid plaques. Autosomal dominant Alzheimer's disease (ADAD) is an early-onset form of $\mathrm{AD}$ which is caused by rare mutations in amyloid $\beta$ (A4) precursor protein (APP), presenilin-1 (PSEN1), or presenilin-2 (PSEN2) that alter A $\beta$ production [1]. Genetic variants also influence the risk of developing the more common late onset form of AD (LOAD). To date the two strongest identified LOAD genetic risk factors are the well-studied apolipoprotein $\varepsilon 4$ (APOE4) allele and several recently identified variants in the triggering receptor expressed on myeloid cells-2 (TREM2) gene

\footnotetext{
* Correspondence: holtzman@neuro.wustl.edu

'Department of Neurology, Washington University School of Medicine, Saint Louis, Missouri 63110, USA

${ }^{4}$ Developmental Biology, Washington University School of Medicine, Saint Louis, Missouri 63110, USA

Full list of author information is available at the end of the article
}

[2-4]. While these variants are not common, since TREM2 variants strongly increase the risk of developing $\mathrm{AD}$, understanding how TREM2 dysfunction affects AD pathology could yield novel therapeutic strategies.

TREM2 encodes a transmembrane protein possessing an extracellular IgG-like ligand binding domain and an intracellular region that associates with the immunoreceptor tyrosine based activating motif (ITAM)-containing signaling adaptor protein DAP12 [5]. Individuals that are homozygous for loss of function mutations in either TREM2 or TYROBP (DAP12) suffer from polycystic lipomembranous osteodysplasia and sclerosing leukoencephalopathy (PLOSL) which is characterized by early onset dementia and cystic bone lesions [6]. Within the brain, TREM2 is expressed by microglia and appears to regulate microglial-mediated phagocytic clearance of cellular debris and the inflammatory response of microglia to pathology, however the endogenous ligand(s) for TREM2 are unknown [7-10]. TREM2 expression is increased in plaque-associated microglia in APP23 and 
TgCRND8 mice suggesting that TREM2 is involved in the microglial response to $A \beta$ plaque deposition $[3,11,12]$. The role of microglia in AD is complex and incompletely understood. Microglia rapidly migrate to $A \beta$ plaque deposits and acquire an amoeboid "activated" morphology $[13,14]$. Pro-inflammatory M1-like microglial activation is generally considered neurotoxic, while pro-phagocytic M2-like activation can lead to microglial clearance of $A \beta$ in murine AD models [15]. Since TREM2 is implicated in regulating the phagocytic and inflammatory function of macrophages, TREM2 dysfunction could conceivably increase $A \beta$ plaque burden through decreased phagocytic clearance of $A \beta$ and/or promote a neurotoxic, inflammatory microglial phenotype in response to $A \beta$ deposition.

In this study we tested whether loss of a single trem 2 allele affected $A \beta$ plaque burden in APPPS1-21 mice[16]. To facilitate analysis of microglia we took advantage of the CX3CR1-GFP mice which in the CNS express GFP specifically within microglia [17]. Although we did not observe a significant difference in $\mathrm{A} \beta$ plaque deposition between $\mathrm{TREM}^{+/+}$and $\mathrm{TREM}^{+/-}$mice, there was a substantial decrease in plaque-associated microglia in TREM $2^{+/-}$ mice compared to TREM2 $2^{+/+}$mice. These data suggest that TREM2 function may affect the microglial response to $A \beta$ pathology.

\section{Results}

TREM2 hemizygosity does not affect $A \beta$ deposition in 3-month old APPPS1-21 mice

Individuals that are heterozygous for TREM2 variants predicted to result in a decrease or loss of TREM2 function in the affected allele, have increased odds of developing AD $[3,4]$. TREM2 expression in microglia is associated with phagocytic clearance of extracellular debris, such as apoptotic neurons, raising the possibility that TREM2 could regulate microglial mediated clearance of extracellular $\mathrm{A} \beta$, and ultimately amyloid plaque deposition [8]. We compared the amount of cortical $\mathrm{A} \beta$ deposition in the early stages of plaque formation using 3-month old APPPS1-21 mice expressing two copies $\left(\right.$ TREM $2^{+/+}$, $\mathrm{CX} \mathrm{CR} 1^{+/ \mathrm{GFP}}$, APPPS1-21, referred to as TREM2 WT) (Figure 1A,C) or one copy of TREM2 $\left(\mathrm{TREM}^{+/-}\right.$, CX3CR1 ${ }^{+/ G F P}$, APPPS1-21, referred to as TREM2 Het) (Figure 1B,D). We observed significantly more A $\beta$ deposition in female mice compared to male mice for both TREM2 WT and TREM2 Het mice; however, we did not detect a significant effect of TREM2 copy number on $A \beta$ deposition (Figure 1E). We further examined whether TREM2 affected amyloid deposition by staining brain sections with $\mathrm{X}-34$, a dye that binds to fibrillar $\mathrm{A} \beta$ [18]. Again, we observed approximately double the amount of amyloid staining in female mice compared to male mice, but no significant difference between TREM2 WT and TREM2 Het mice (Figure 1F). We also biochemically assessed $A \beta$ accumulation by measuring the level of PBS insoluble $A \beta_{40}$ and $A \beta_{42}$ from TREM2 WT and TREM2 Het cortical tissue. As expected given the immunohistological data, female mice had significantly higher amounts of insoluble $A \beta_{40}$ and $A \beta_{42}$ than male mice. However, there was no genotype-dependent difference in the levels of insoluble $A \beta_{40}$ or $A \beta_{42}$ (Figure 2). Taken together, these data suggest that TREM2 hemizygosity has no effect on $A \beta$ plaque burden during the early stages of $A \beta$ deposition.

\section{Altered microglial response to $A \beta$ plaque deposits in TREM2 Het mice}

Microglia migrate to sites of plaque deposition and acquire an activated state that may restrict plaque growth or produce a neurotoxic inflammatory response [13,14]. We hypothesized that TREM2 could regulate the microglial localization around amyloid plaques. To test this hypothesis we compared the percentage of area covered by GFPexpressing microglia within a $20 \mu \mathrm{m}$ radius of the edge of A $\beta$ plaques in 3-month old TREM2 WT and TREM2 Het mice. Since female mice exhibited more robust $A \beta$ deposition than male mice, we chose to analyze the microglial response in female mice. TREM2 Het mice exhibited a decrease in the density of plaque-associated microglia compared to TREM2 WT mice (Figure 3G). Microglial soma were also smaller in TREM2 Het compared to TREM2 WT mice (Figure $3 \mathrm{H}$ ). The overall effect of the reduced number and size of plaque-associated microglia in TREM2 Het mice was very strong; there was a 40\% reduction in microglial coverage around $A \beta$ plaques in TREM2 Het mice compared to TREM2 WT mice (Figure 3I). Thus, although TREM2 WT and TREM2 Het mice exhibited similar levels of $A \beta$ deposition, there was a significant decrease in microglial localization near $A \beta$ plaques.

\section{No significant alterations in gene expression or cytokine levels in 3-month old TREM2 Het mice}

Given the decreased localization of microglia to $A \beta$ plaques and altered morphology of plaque-associated microglia, we next tested whether there were alterations in the expression levels of microglial markers associated with $\mathrm{AD}$, or in the inflammatory milieu of the brain, of TREM2 Het compared to TREM2 WT mice. We first compared the mRNA levels in cortical tissue of the microglial markers TREM2, C1qa, Aif1, Itgam (CD11b/CR3), and CX3CR1. Predictably, the relative level of TREM2 mRNA in TREM2 Het mice was $~ 50 \%$ that of TREM2 WT mice (Figure 4A). The expression levels of the other microglial markers were not significantly different following correction for multiple comparisons. Interestingly though, there was a trend towards an approximately 35\% decrease in C1qa levels in TREM2 Het compared to TREM2 WT mice (corrected p-value 0.091) (Figure 4A). We also 


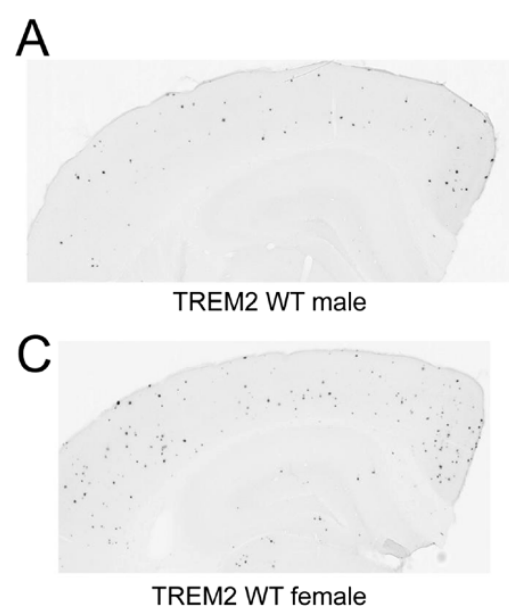

TREM2 WT female

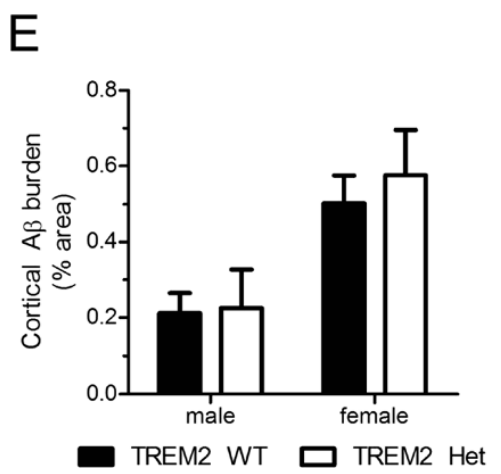

B

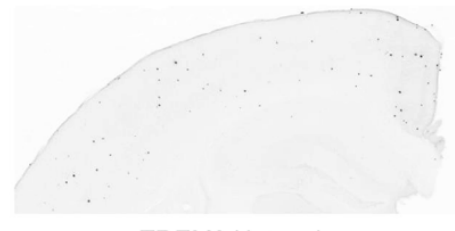

TREM2 Het male

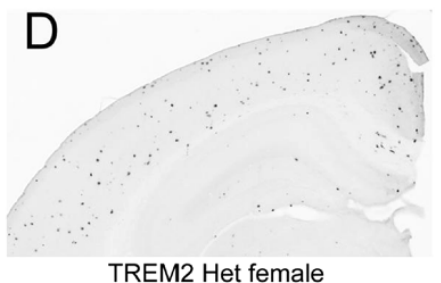

$\mathrm{F}$

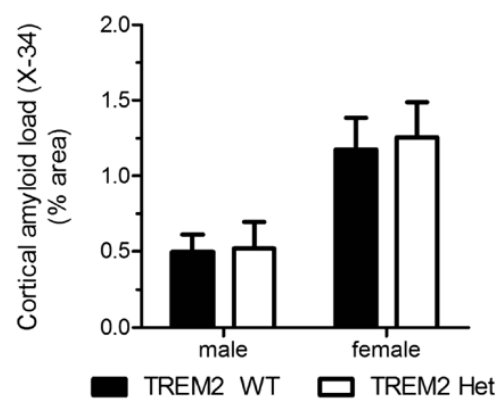

Figure 1 TREM2 heterozygosity does not affect A $\beta$ plaque deposition in 3-month old APPPS1-21 mice. (A-D) Representative coronal brain sections from 3-month old from male TREM2 WT (A), male TREM2 Het (B), female TREM2 WT (C) and female TREM2 Het (D). Sections were immunostained with a biotinylated anti-A $\beta$ antibody HJ3.4. (E) Quantification of the percentage of cortical area occupied by $A \beta$ immunostaining. Two-way ANOVA analysis found a significant effect of gender $\left(F_{1,39}=13.63, p=0.0007\right)$, but not genotype $\left(F_{1,39}=0.25, p=0.62\right)$. (F) Quantification of the percentage of cortical area occupied by $X$-34 staining. Two-way ANOVA analysis found a significant effect of gender $\left(F_{1,39}=14.33\right.$, $p=0.0005$ ), but not genotype $\left(F_{1,39}=0.08, p=0.78\right.$; TREM2 WT (male, $n=12$; female, $n=12$ ) TREM2 Het (male, $n=9$; female, $\left.n=10\right)$ ). Data are presented as mean $\pm \mathrm{SEM}$.
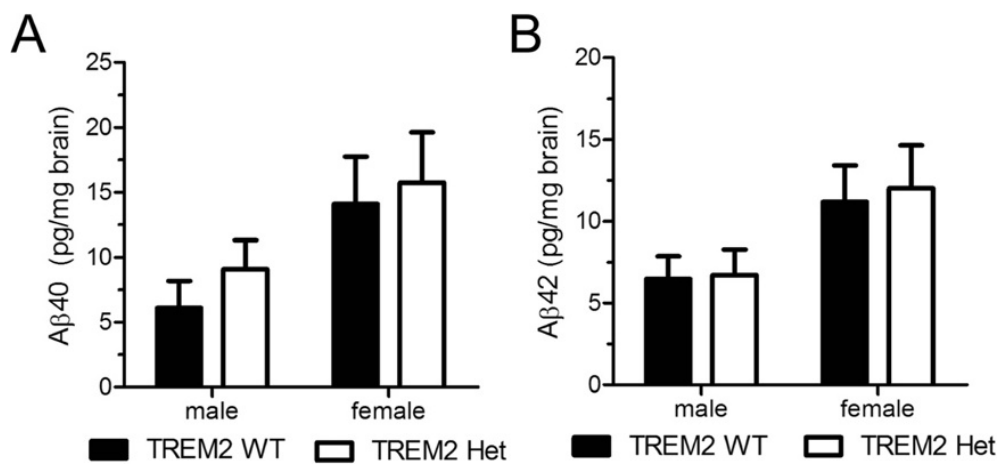

Figure 2 TREM2 heterozygosity does not affect PBS-insoluble A $\beta$ levels in 3-month old APPPS1-21 mice. (A) Mean concentrations of PBS-insoluble $A \beta_{40}$ in cortical tissue from TREM2 WT (male, $n=13$; female, $n=12$ ) and TREM2 Het (male, $n=8$; female $n=10$ ) mice were determined by ELISA. Two-way ANOVA analysis found a significant effect of gender $\left(F_{1,38}=5.49, p=0.02\right)$, but not genotype $\left(F_{1,38}=0.55, p=0.46\right)$. (B) Mean concentrations of PBS-insoluble $A \beta_{42}$ in cortical tissue from TREM2 WT (male, $n=13$; female, $n=12$ ) and TREM2 Het (male, $n=8$; female $\mathrm{n}=10)$ mice were determined by ELISA. Two-way ANOVA analysis found a significant effect of gender $\left(F_{1,38}=5.96, p=0.02\right)$, but not genotype $\left(F_{1,38}=0.07, p=0.79\right)$. Data are presented as mean \pm SEM. 

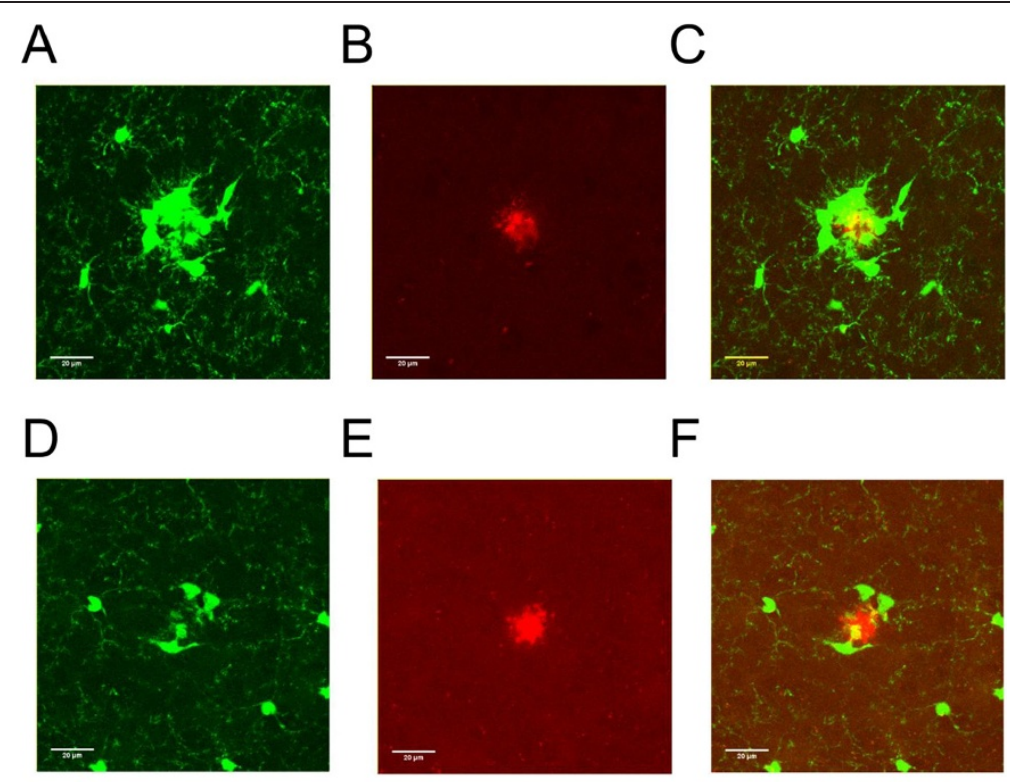

$\mathrm{F}$

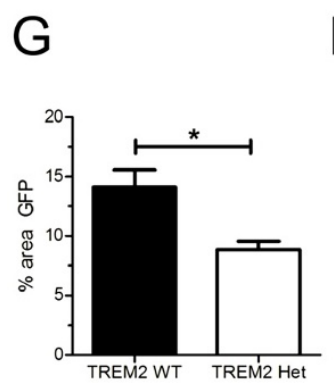

$\mathrm{H}$
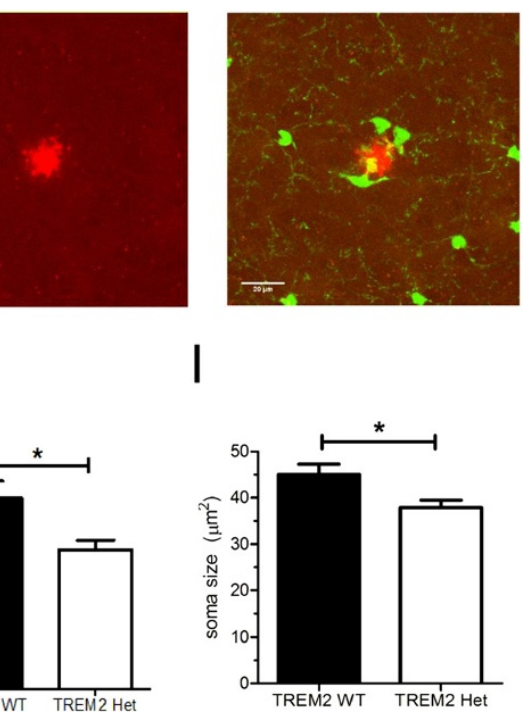

Figure 3 Decreased plaque-associated microglia in TREM2 Het mice. (A-F) Representative images of Alexa568-HJ3.4-stained plaque and GFP-expressing microglia from TREM2 WT (A-C) and TREM2 Het (D-F) mice. (G) The number of microglia per $100 \mu \mathrm{m}^{2}$ within a $20 \mu \mathrm{m}^{2}$ radius of an A $\beta$ plaque in TREM2 WT mice $(25.1 \pm 2.25, n=10)$ and TREM2 Het mice $(18.3 \pm 1.24, n=9)$ was compared using a Mann-Whitney test $(p=0.03)$. (H) The mean soma size off plaque-associated microglia in TREM2 WT mice $\left(45.0 \pm 2.23 \mu \mathrm{m}^{2}, \mathrm{n}=10\right)$ and TREM2 Het mice (37.9 \pm $1.57 \mu \mathrm{m}^{2}, \mathrm{n}=9$ ) was compared using a Mann-Whitney test $(\mathrm{p}=0.03)$. (I) The percent area covered by plaque-associated microglia in TREM2 WT mice $(14.1 \pm 1.4 \%, n=10)$ and TREM2 Het mice $(8.8 \pm 0.71 \%, n=9)$ was compared using a Mann-Whitney test $(p=0.01)$.

compared the expression level of NOS2 which can be upregulated during pro-inflammatory microglial responses [19]. Although not statistically significant, there was a 33\% decrease in NOS2 expression in TREM2 Het mice as compared to WT (corrected p-value 0.090) (Figure 4A). To more broadly characterize the effects of reduced TREM2 expression on the inflammatory milieu of the brain in response to $A \beta$ pathology we measured the levels of cytokines from cortical tissue lysates of TREM2 WT and TREM2 Het mice (Figure 4B-D). Many inflammatory cytokines, such as TNF $\alpha$ and IL1 $\beta$, fell below the limit of detection, possibly due to the early stage of $A \beta$ pathology detected in 3-month old APPPS1-21 mice. While we did not detect any significant differences in cytokine levels between TREM2 WT and TREM2 Het mice, there was a trend towards lower levels of the pro-inflammatory cytokine IL1 $\alpha$ in TREM2 Het $(24.0 \mathrm{pg} / \mathrm{mL} \pm 1.3, \mathrm{n}=6)$ compared to TREM2 WT $(29.7 \mathrm{pg} / \mathrm{mL} \pm 1.3, \mathrm{n}=6)$ mice (corrected p-value 0.12) (Figure 4B). Overall, the qRT-
PCR and cytokine data suggest a trend towards lower inflammation in TREM2 Het compared to TREM2 WT mice, consistent with the decreased microglial localization to $A \beta$ plaque deposits in TREM2 Het mice.

\section{No difference in $A \beta$ deposition or microglial activation} marker expression in 7-month old TREM2 WT and TREM2 Het mice

We next assessed whether TREM2 hemizygosity would alter $A \beta$ plaque burden in more advanced stages of pathology by comparing the level of cortical $A \beta$ plaque deposition in 7-month old TREM2 WT and TREM2 Het mice. At 7-months of age both TREM2 WT and TREM2 Het mice exhibited robust cortical $A \beta$ plaque deposition (Figure 5A-B). However, as in 3-month old mice, there was no significant difference in the level of cortical $A \beta$ plaque between TREM2 WT and TREM2 Het mice (Figure 5C). 

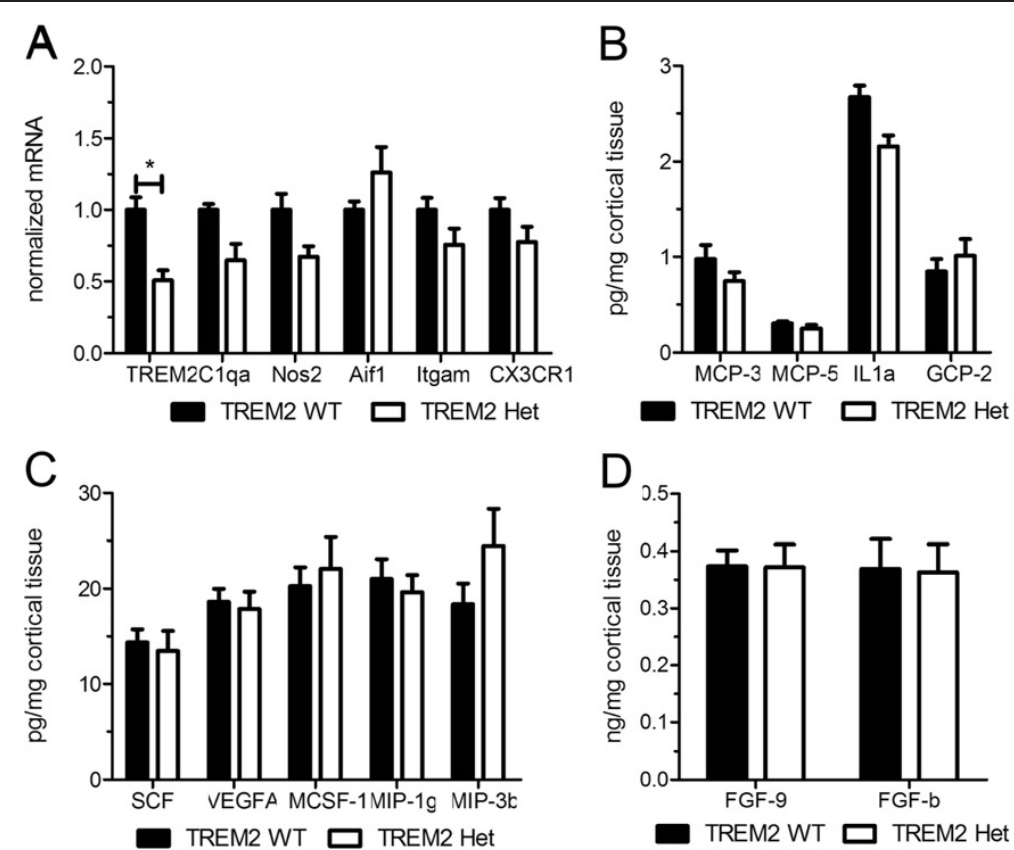

Figure 4 TREM2 heterozygosity does not significantly affect the inflammatory milieu in 3-month old APPPS1-21 mice. (A) Quantification of relative gene expression of microglial markers and NOS2 in TREM2 WT and TREM2 Het mice ( $n=4-6$ mice/genotype). For each mRNA analyzed TREM2 Het values were normalized and compared to TREM2 WT values using a t-test followed by a Benjamini-Hochberg p-value correction for multiple comparisons. (B-D) Levels of inflammatory cytokines in cortical tissue from TREM2 WT $(n=6)$ and TREM2 Het $(n=6)$ mice were compared using a t-test followed by Benjamini-Hochberg p-value correction for multiple comparisons. Cytokine levels are plotted on different axis for clarity of presentation. All data are presented as mean $\pm \mathrm{SEM},{ }^{*}$ corrected $\mathrm{p}<0.05$.

A

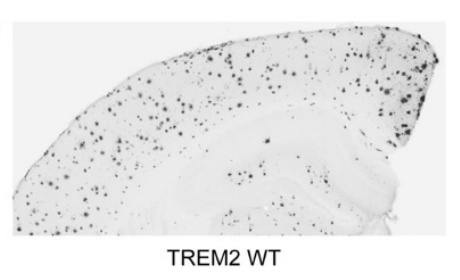

C

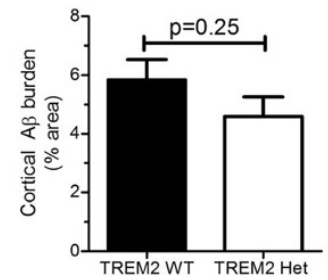

B

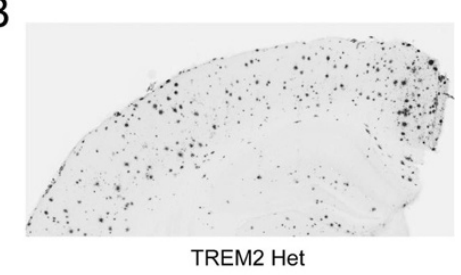

D

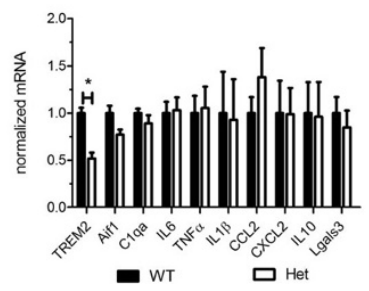

Figure 5 TREM2 hemizygosity does not significantly affect $A \beta$ plaque burden or expression of $M 1 / M 2$ microglial markers in 7-month old APPPS1-21 mice. (A and B) Representative coronal brain sections from 7-month old female TREM2 WT (A) and TREM2 Het (B) mice. Sections were immunostained with the biotinylated anti-A 3 antibody, HJ3.4. (C) Quantification of the cortical area occupied by AB immunostaining. TREM2 WT $(5.85 \pm 0.69 \%, n=9)$ and TREM2 Het $(4.60 \pm 0.66 \%, n=7)$ were statistically compared using a Mann Whitney test $(p=0.25)$. (D) Quantification of microglial mRNA expression in TREM2 WT and TREM2 Het mice. For each mRNA examined TREM2 Het were normalized and compared to TREM2 WT mice using a t-test followed by Benamini-Hochberg p-value correction for multiple comparisons. All data are presented as mean \pm SEM ( $n=3-7$ mice per group), ${ }^{*} p<0.05$. 
To determine if there were differences in the microglial activation state at a more advanced stage of $A \beta$ pathology we isolated microglia from 7-month old TREM2 WT and TREM2 Het mice and performed qRTPCR to measure the expression level of genes associated with M1 or M2 polarization. As expected we observed a $\sim 50 \%$ reduction in TREM2 mRNA levels in TREM2 Het mice (Figure 5D). However, we observed no difference in the expression level of M1 markers IL1 $\beta$, IL6, TNF $\alpha$, CCL2, or CXCL2, or in the level of M2 markers IL10 and Lgals3 (Figure 5D). We also observed no statistically significant difference in the expression level of C1qa or Aif1 between 7-month old TREM2 WT and TREM2 Het mice. These data indicate that there is no effect of TREM2 hemizygosity on $A \beta$ plaque deposition or microglial gene expression that we assessed during later stages of $\mathrm{A} \beta$ pathology.

\section{Discussion}

TREM2 variants, particularly the $\mathrm{R} 47 \mathrm{H}$ mutation, strongly increase the risk of developing $\mathrm{AD}$, however how TREM2 affects $\mathrm{AD}$ and $\mathrm{AD}$ pathology is unknown $[3,4]$. Here, we report a decrease in the number and size of plaque-associated microglia in 3-month old TREM2 Het mice as compared to TREM2 WT mice, suggesting that TREM2 regulates the microglial response to $A \beta$ plaque deposition. To the best of our knowledge this is the first report of an observable microglial phenotype in hemizygous TREM2 mice. As the resident macrophages in the brain, microglia are hypothesized to mediate both a beneficial phagocytic clearance of $A \beta$ from the brain, and a detrimental chronic inflammatory phenotype resulting in neurotoxicity [20]. Longitudinal in vivo imaging studies demonstrate that microglia rapidly form clusters around $\mathrm{A} \beta$ deposits, although the molecular determinants of microglial migration to $A \beta$ deposits are poorly understood $[13,14]$. Plaque-associated microglia also assume an amoeboid morphology with larger cell somas than non-plaque associated microglia [21]. Our data indicates that plaque-associated microglia in TREM2 Het mice are smaller than in TREM2 WT mice, which may indicate a defect in microglial activation.

We observed a reduced number of plaque-associated microglia in TREM2 Het mice compared to TREM2 WT mice. The reduced microglial response in TREM2 Het mice could result from defective microglial activation, migration, survival, or proliferation. Genetic network analysis of TREM2 expressed in the brain linked TREM2 to genes involved in regulating cytoskeletal rearrangements required for phagocytosis and migration [22]. In the periphery TREM2-DAP12 signaling is important for chemotaxic macrophage migration to the lungs following exposure to cigarette smoke, supporting the hypothesis that TREM2 can regulate macrophage migration to sites of injury [23]. Microglial proliferation also contributes to the population of plaque associated microglia [21,24]. TREM2 regulates macrophage-colony stimulating factor (M-CSF)-induced osteoclast precursor cell proliferation [25]. Microglia express colony-stimulating factor 1 receptor (CSF1R) which is regulates both microglial proliferation and viability [26-28]. Therefore, one potential explanation is that TREM2 is important for CSF1R-dependent responses to pathology. Further studies will be needed to characterize the mechanistic basis for how TREM2 regulates the number of plaque-associated microglia.

Despite the reduction in plaque-associated microglia, we did not observe any statistically significant difference in the expression of inflammatory cytokines or genes associated with microglial activation in TREM2 Het and TREM2 WT mice in either 3-month or 7-month old animals. TREM2-DAP12 signaling inhibits Toll-like receptor (TLR)-dependent cytokine production and bone marrow derived macrophages from TREM2 KO mice exhibit increased expressed inflammatory cytokine production in response to microbial stimulation [29]. Similarly, knockdown of TREM2 expression in microglia co-cultured with apoptotic neurons resulted in increased production of TNF $\alpha$ and NOS2 [8]. In contrast, TREM2 KO mice exhibited decreased inflammatory cytokine production compared to TREM2 WT mice in the middle cerebral artery occlusion model of stroke concomitant with decreased localization of activated microglia within the glial scar [10]. Thus the overall effect of TREM2 dysfunction on inflammatory signaling may depend upon the precise pathological context. It is also important to note that the effects of TREM2 on cytokine production were described in the context of a complete loss of TREM2 function, such as occurs in PLOSL. TREM2 Het mice may retain sufficient TREM2 function to properly regulate cytokine production. One caveat to our study is that although we did not detect a compensatory upregulation of TREM2 at the mRNA level, we were unable to quantify TREM2 protein expression in brain lysate by western blot using currently available reagents. Therefore, we cannot exclude the possibility that TREM2 protein expression is post-transcriptionally modified to compensate for loss of TREM2 expression.

Although we did not detect a TREM2-dependent difference in $A \beta$ plaque burden, another microglialassociated protein genetically associated with $\mathrm{AD}, \mathrm{CD} 33$, appears to substantially influence $\mathrm{A} \beta$ deposition [30-33]. $\mathrm{CD} 33$ appears to inhibit microglial uptake of $\mathrm{A} \beta$ in vitro and genetic deletion of $C D 33$ in $\mathrm{APP}_{\mathrm{SWE}} / \mathrm{PS}_{\triangle \mathrm{E} 9}$ mice reduces $A \beta$ plaque burden [30]. Furthermore, individuals possessing CD33 variants that were associated with increased odds of developing $\mathrm{AD}$ exhibited higher CD33 expression and protective CD33 variants resulted in 
lower CD33 expression [30,34]. Taken together, the effects of CD33 on microglial clearance of $A \beta$ and the TREM2-dependent effects on plaque-associated microglia reported in this study, suggest that alterations in microglial function may impact different stages of $\mathrm{AD}$ pathogenesis.

Although we observed a strong decrease in microglial localization near $\mathrm{A} \beta$ plaques at 3 months, we did not observe a significant difference in $A \beta$ plaque burden between TREM2 WT and TREM2 Het mice at either 3 or 7 months. One hypothesized function of plaque-associated microglia is to restrict the growth of $A \beta$ plaque, which would imply that a decrease in plaque-associated microglia could result in larger $A \beta$ plaques [14]. However, a previous study demonstrated that a four-week ablation of microglia had no effect on A $\beta$ plaque burden in APPPS1-21 or APP23 mice, suggesting that, over the short term, $A \beta$ plaque growth was not significantly impacted by microglia [35]. TREM2 is thought to promote microglial phagocytic activity, and therefore decreased functional TREM2 expression could result in reduced clearance of $A \beta$ and a subsequent increase in plaque deposition [8]. Although in this study we did not test the phagocytic function of TREM2, the lack of significant effect of TREM2 hemizygosity on $A \beta$ plaque burden does not support the hypothesis that TREM2 regulates $A \beta$ deposition. The discovery that variants in TREM2 strongly increase the odds of developing not only AD, but also Parkinson's disease, amyotrophic lateral sclerosis, and frontotemporal dementia underscores the important role that the innate immune system plays in neurodegenerative disease and suggests that TREM2 subserves a beneficial microglial response in a variety of pathologies [36,37].

\section{Conclusions}

Here, we report that loss of a single TREM2 allele decreases the number and size of plaque-associated microglia in 3-month old APPPS1-21 mice, but has no effect on total amyloid burden in either 3- or 7-month old APPPS1-21 mice. Individuals possessing a single variant TREM2 allele have substantially increased odds of developing $\mathrm{AD}$, however, the role of TREM2 in $\mathrm{AD}$ pathology is unknown. To the best of our knowledge, this is the first report linking loss of a functional TREM2 allele to an observable phenotype in the presence of $A \beta$ pathology.

\section{Methods}

\section{Animals}

APPPS1-21 transgenic mice (APP (KM670/671NL)/PS1 (L166P), gift of Mathias Jucker) were crossed with $\mathrm{TREM}^{-/-} \mathrm{x}$ CX3CR $1^{\text {GFP/GFP }}$ mice or $\mathrm{TREM}^{+/+\mathrm{x}}$ CX3CR1 ${ }^{\text {GFP/GFP }}$ mice to generate APPPS1-21 $\times$ TREM2 $^{+/-}$ CX3CR $1^{+/ G F P}$ (TREM2 Het) and APPPS1-21 $\mathrm{x}$ $\mathrm{TREM}^{+/+} \times \mathrm{CX} 3 \mathrm{CR} 1^{+/ G F P}$ (TREM2 WT) mice. All mice were maintained on a C57BL/6 background and all animal work was in accordance with guidelines established by the Animals Studies Committee at Washington University.

\section{Amyloid plaque analysis}

Mice underwent transcardial perfusion with PBS ( $\mathrm{pH}$ 7.4) followed by removal of the brain. Half the brain was fixed in $4 \%$ paraformaldehyde for 24 hours $\left(4^{\circ} \mathrm{C}\right)$ and half was either frozen on dry ice and stored at $-80^{\circ} \mathrm{C}$ for biochemical and qPCR analysis or processed to isolate microglial cells. Fixed hemibrains were cryoprotected in $30 \%$ sucrose in PBS ( $\mathrm{pH} 7.4$ ), frozen in dry ice, and serial coronal sections (50 $\mu \mathrm{m}$ thick) from the rostral anterior commissure to the caudal hippocampus were collected using a freezing sliding microtome. Three sections, $300 \mu \mathrm{m}$ apart, were stained for $\mathrm{A} \beta$ using biotinylated HJ3.4 (anti-N-terminal $A \beta$ antibody) and developed with DAB using a VECTASTAIN ABC Elite kit (Vector Labs) per manufacturer's directions. To stain amyloid, three sections, $300 \mu \mathrm{m}$ apart, were stained with X-34 dye $(10 \mu \mathrm{M})$. HJ3.4 and X-34 stained sections were imaged using a NanoZoomer slide scanner (Hamamatsu Photonics) and the percent cortical area covered by HJ3.4 or X-34 staining was quantified by an experimenter blinded to the genotype and gender of the animal.

\section{Microglial isolation}

A single cell suspension was generated from mouse hemibrains using a neural tissue dissociation kit (Miltenyi Biotec, 130-093-231) and gentleMACS Dissociator (Miltenyi Biotec) according to manufacturer recommended protocols. Microglia cells were then enriched by labeling the cells with mouse CD45 MicroBeads (MIltenyi Biotec, 130-052-301) and subsequent purification using a magnetic column. Microglia cells were then FACS sorted based on the surface markers of CD $45^{\text {lo }}$, $\mathrm{CD}_{11} \mathrm{~b}^{\text {high }}$ and GFP expression.

\section{Real-time qPCR analysis}

RNA was extracted from frozen cortical tissue using the RNeasy kit (Qiagen) or from adult microglia using the RNeasy Micro kit (Qiagen). Reverse transcription was performed using a High-Capacity cDNA Reverse Transcription Kit (Life Technologies). Real-time qPCR was conducted with TaqMan primers (Life Technologies)[19] and the TaqMan Universal PCR Master Mix (Life Technologies) using an ABI Prizm 7500 thermocycler. Relative gene expression levels in TREM2 WT and TREM2 Het mice were compared using the $\Delta \Delta C_{t}$ method with $\beta$-actin used as a reference.

\section{Biochemical analysis of insoluble $A \beta$ levels}

Cortical tissue was sequentially homogenized in PBS $(\mathrm{pH}$ 7.4) and $5 \mathrm{M}$ guanidine-Tris buffer $(\mathrm{pH} \mathrm{8.0)}$ in the 
presence of protease inhibitors (Roche). $A \beta_{40}$ and $A \beta_{42}$ levels were quantitatively measured by sandwich ELISA using either HJ2 (anti-A $\beta_{35-40}$ ) or HJ7.4 (anti-A $\beta_{37-42}$ ) as capture antibodies and biotinylated HJ5.1 (anti-A $\beta_{13-28}$ ) as the detection antibody. Following incubation with poly-horseradish peroxidase-20 (Fitzgerald) ELISAs were developed using Super Slow ELISA TMB (Sigma).

\section{Microglia quantification}

Alexa568-HJ3.4-stained brain sections were imaged using a $40 \mathrm{x}$ water-immersion objective (Zeiss, $\mathrm{NA}=1.2$ ) on a Zeiss LSM5 confocal microscope. All images were acquired and analyzed by an experimenter blinded to the genotype of the animal. Z-series stack images of randomly selected plaques within the lateral half of the cortex located above the hippocampus were then sequentially acquired for Alexa568 and GFP fluorescence ( 12 optical sections, $3 \mu \mathrm{m}$ apart). All images were acquired using identical acquisition parameters as 8-bit, $1024 \times 1024$ arrays. Z-series stacks were then converted to maximum intensity projections and threshold adjusted to isolate specific GFP fluorescence. Plaque-associated microglial coverage was assessed by measuring the percent area covered by GFP fluorescence within $20 \mu \mathrm{m}$ of the edge of the plaque, including the area of the plaque itself. To assess the number and size of plaque-associated microglia, thresholded images were segmented using a watershed function and the number and area of microglia assessed in ImageJ using a minimum size cut-off of $16 \mu \mathrm{m}^{2}$.

\section{Cytokine analysis}

Cortical tissue from 3-month old APPPS1-21 $\times \mathrm{TREM}^{+/+\mathrm{x}}$ CX3CR1 ${ }^{+/ G F P}$ and APPPS1-21 x TREM2 ${ }^{+/-}$CX3CR1 $1^{+/ G F P}$ was homogenized in $9 \mathrm{x}$ volumes lysis buffer $(50 \mathrm{mM}$ Tris$\mathrm{HCl}$ (pH7.4), 2 mM EDTA, protease inhibitors). Lysates were centrifuged for $2 \mathrm{~min}$ at 13,000xg and analyzed using the Rodent Cytokine Multi-Analyte Profile (Myriad RBM).

\section{Statistics}

Amyloid plaque immunohistochemistry and insoluble $\mathrm{A} \beta$ levels between male and female TREM2 WT and TREM2 Het mice were statistically analyzed using 2-way ANOVA $(\alpha=0.05)$. The number, soma size, and percentarea covered by plaque-associated microglia were compared using a Mann Whitney test. RT-qPCR results from TREM2 WT and TREM2 Het groups were compared by t-test using a Benjamini-Hochberg correction for multiple comparisons. P-values less than 0.05 were considered statistically significant.

\footnotetext{
Abbreviations

AD: Alzheimer's disease; ADAD: Autosomal dominant Alzheimer's disease; APP: Amyloid $\beta$ (A4) precursor protein; PSEN1: Presenilin-1; PSEN2: Presenilin-2; LOAD: Late onset Alzheimer's disease; apoE: Apolipoprotein E; TREM2: Triggering receptor expressed on myeloid cells-2;
}

ITAM: Immunoreceptor tyrosine based activating motif; PLOSL: Polycystic lipomembranous osteodysplasia and sclerosing leukoencephalopathy; M-CSF: Macrophage colony stimulating factor; CSF1R: Colony stimulating factor 1 receptor.

\section{Competing interests}

$\mathrm{DMH}$ co-founded and is on the scientific advisory board of C2N Diagnostics and currently serves as a consultant for Astra Zeneca, Eli Lilly, and Genentech.

\section{Authors' contributions}

Tissue immunohistochemistry and $X-34$ staining were performed by JDU, $M B F, A S, T E M, F R S$, and $H J . A B$ and $X-34$ staining were quantified by MBF and JDU. Microglial isolation was performed by YW and JDU. Tissue biochemistry was performed by MBF and JDU. Microglial localization was quantified by JDU. RT-qPCR was performed by JDU and AS. Experiments were conceived and designed by JDU, DMH, MC, and LP. Manuscript was written by JDU and critically reviewed by DMH, MC, and LP. All authors read and approved the final manuscript.

\section{Acknowledgements}

Funded by grants from Cure Alzheimer's Fund (DMH), NIH (F32-NS083187-01A1) (JDU), L.P. is a Harry Weaver Neuroscience Scholar of the National Multiple Sclerosis Society (JF 2144A2/1). We thank Mathias Jucker (University of Tubingen) for providing APPPS1-21 mice.

\section{Author details}

'Department of Neurology, Washington University School of Medicine, Saint Louis, Missouri 63110, USA. ²Department of Pathology and Immunology, Washington University School of Medicine, Saint Louis, Missouri 63110, USA. ${ }^{3}$ Department of Medicine, Washington University School of Medicine, Saint Louis, Missouri 63110, USA. ${ }^{4}$ Developmental Biology, Washington University School of Medicine, Saint Louis, Missouri 63110, USA. ${ }^{5}$ Hope Center for Neurological Disorders, Washington University School of Medicine, Saint Louis, Missouri 63110, USA. ${ }^{6}$ Knight Alzheimer's Disease Research Center, Washington University School of Medicine, Saint Louis, Missouri 63110, USA.

Received: 9 March 2014 Accepted: 20 May 2014

Published: 3 June 2014

\section{References}

1. Tanzi RE: The Genetics of Alzheimer Disease. In The Biology of Alzheimer Disease. Edited by Selkoe DJ, Mandelkow E, Holtzman DM. New York: Cold Spring Harbor Press; 2011:249-258.

2. Corder EH, Saunders AM, Strittmatter WJ, Schmechel DE, Gaskell PC, Small GW, Roses AD, Haines JL, Pericak-Vance MA: Gene dose of apolipoprotein E type 4 allele and the risk of Alzheimer's disease in late onset families. Science 1993, 261:921-923.

3. Guerreiro R, Wojtas A, Bras J, Carrasquillo M, Rogaeva E, Majounie E, Cruchaga C, Sassi C, Kauwe JSK, Younkin S, Hazrati L, Collinge J, Pocock J, Lashley T, Williams J, Lambert JC, Amouyel P, Goate A, Rademakers R, Morgan K, Powell J, St George-Hyslop P, Singleton A, Hardy J: TREM2 variants in Alzheimer's disease. New Engl J Med 2013, 368:117-127.

4. Jonsson T, Stefansson H, Steinberg S, Jonsdottir I, Jonsson PV, Snaedal J, Bjornsson S, Huttenlocher J, Levey Al, Lah JJ, Rujescu D, Hampel H, Giegling I, Andreassen OA, Engedal K, Ulstein I, Djurovic S, Ibrahim-Verbaas C, Hofman A, Ikram MA, van Duijn CM, Thorsteinsdottir U, Kong A, Stefansson $\mathrm{K}$ : Variant of TREM2 associated with the risk of Alzheimer's disease. New Engl J Med 2013, 368:107-116.

5. Bouchon A, Hernández-Munain C, Cella M, Colonna M: A Dap12-mediated pathway regulates expression of $\mathrm{Cc}$ chemokine receptor 7 and maturation of human dendritic cells. J Exp Med 2001, 194:1111-1122.

6. Paloneva J, Manninen T, Christman G, Hovanes K, Mandelin J, Adolfsson R, Bianchin M, Bird T, Miranda R, Salmaggi A, Tranebjaerg L, Konttinen Y, Peltonen L: Mutations in two genes encoding different subunits of a receptor signaling complex result in an identical disease phenotype. Am J Hum Genet 2002, 71:656-662.

7. Schmid CD, Sautkulis LN, Danielson PE, Cooper J, Hasel KW, Hilbush BS, Sutcliffe JG, Carson MJ: Heterogeneous expression of the triggering receptor expressed on myeloid cells-2 on adult murine microglia. J Neurochem 2002, 83:1309-1320. 
8. Takahashi K, Rochford CDP, Neumann H: Clearance of apoptotic neurons without inflammation by microglial triggering receptor expressed on myeloid cells-2. J Exp Med 2005, 201:647-657.

9. Piccio L, Buonsanti C, Mariani M, Cella M, Gilfillan S, Cross AH, Colonna M, Panina-Bordignon P: Blockade of TREM-2 exacerbates experimental autoimmune encephalomyelitis. Eur J Immunol 2007, 37:1290-1301.

10. Sieber MW, Jaenisch N, Brehm M, Guenther M, Linnartz-Gerlach B, Neumann $\mathrm{H}$, Witte OW, Frahm C: Attenuated inflammatory response in triggering receptor expressed on myeloid cells 2 (TREM2) knock-out mice following stroke. PLoS One 2013, 8:e52982.

11. Melchior B, Garcia AE, Hsiung BK, Lo KM, Doose JM, Thrash JC, Stalder AK, Staufenbiel M, Neumann $H$, Carson MJ: Dual induction of TREM2 and tolerance-related transcript, Tmem176b, in amyloid transgenic mice: implications for vaccine-based therapies for Alzheimer's disease. ASN Neuro 2010, 2:e00037.

12. Frank S, Burbach GJ, Bonin M, Walter M, Streit W, Bechmann I, Deller T: TREM2 is upregulated in amyloid plaque-associated microglia in aged APP23 transgenic mice. Glia 2008, 56:1438-1447.

13. Meyer-Luehmann M, Spires-Jones TL, Prada C, Garcia-Alloza M, de Calignon A, Rozkalne A, Koenigsknecht-Talboo J, Holtzman DM, Bacskai BJ, Hyman BT: Rapid appearance and local toxicity of amyloid-beta plaques in a mouse model of Alzheimer's disease. Nature 2008, 451:720-724.

14. Bolmont T, Haiss F, Eicke D, Radde R, Mathis CA, Klunk WE, Kohsaka S, Jucker M, Calhoun ME: Dynamics of the microglial/amyloid interaction indicate a role in plaque maintenance. J Neurosci 2008, 28:4283-4292.

15. Aguzzi A, Barres BA, Bennett ML: Microglia: scapegoat, saboteur, or something else? Science 2013, 339:156-161.

16. Radde R, Bolmont T, Kaeser SA, Coomaraswamy J, Lindau D, Stoltze L, Calhoun ME, Jäggi F, Wolburg H, Gengler S, Haass C, Ghetti B, Czech C, Hölscher C, Mathews PM, Jucker M: A 342 -driven cerebral amyloidosis in transgenic mice reveals early and robust pathology. EMBO Reports 2006, 7:940-946.

17. Jung S, Aliberti J, Graemmel P, Sunshine MJ, Kreutzberg GW, Sher A, Littman DR: Analysis of fractalkine receptor CX3CR1 function by targeted deletion and green fluorescent protein reporter gene insertion. Mol Cell Biol 2000, 20:4106-4114.

18. Styren SD, Hamilton RL, Styren GC, Klunk WE: X-34, a fluorescent derivative of Congo red: a novel histochemical stain for Alzheimer's disease pathology. J Histochem Cytochem 2000, 48:1223-1232.

19. Gaikwad S, Heneka M: Studying M1 and M2 States in Adult Microglia. In Microglia. Volume 1041. Edited by Joseph B, Venero JL. New York: Humana Press; 2013:185-197. Methods in Molecular Biology].

20. Mosher Kl, Wyss-Coray T: Microglial dysfunction in brain aging and Alzheimer's disease. Biochem Pharmacol 2014, 88:594-604.

21. Bornemann KD, Wiederhold KH, Pauli C, Ermini F, Stalder M, Schnell L, Sommer B, Jucker M, Staufenbiel M: Abeta-induced inflammatory processes in microglia cells of APP23 transgenic mice. Am J Pathol 2001 158:63-73.

22. Forabosco P, Ramasamy A, Trabzuni D, Walker R, Smith C, Bras J, Levine AP, Hardy J, Pocock JM, Guerreiro R, Weale ME, Ryten M: Insights into TREM2 biology by network analysis of human brain gene expression data. Neurobiol Aging 2013, 34:2699-2714.

23. Koth LL, Cambier CJ, Ellwanger A, Solon M, Hou L, Lanier LL, Abram CL, Hamerman JA, Woodruff PG: DAP12 is required for macrophage recruitment to the lung in response to cigarette smoke and chemotaxis toward CCL2. J Immunol 2010, 184:6522-6528.

24. Bondolfi L, Calhoun M, Ermini F, Kuhn HG, Wiederhold K-H, Walker L, Staufenbiel M, Jucker M: Amyloid-associated neuron loss and gliogenesis in the neocortex of amyloid precursor protein transgenic mice. J Neurosci 2002, 22:515-522.

25. Otero K, Shinohara M, Zhao H, Cella M, Gilfillan S, Colucci A, Faccio R, Ross FP, Teitelbaum SL, Takayanagi H, Colonna M: TREM2 and $\beta$-catenin regulate bone homeostasis by controlling the rate of osteoclastogenesis. J Immunol 2012, 188:2612-2621.

26. Elmore Monica RP, Najafi Allison R, Koike Maya A, Dagher Nabil N, Spangenberg Elizabeth E, Rice Rachel A, Kitazawa M, Matusow B, Nguyen H, West Brian L, Green Kim N: Colony-stimulating factor 1 receptor signaling is necessary for microglia viability, unmasking a microglia progenitor cell in the adult brain. Neuron 2014, 82:380-397.
27. Gómez-Nicola D, Fransen NL, Suzzi S, Perry VH: Regulation of microglial proliferation during chronic neurodegeneration. J Neurosci 2013, 33:2481-2493.

28. Wang Y, Szretter KJ, Vermi W, Gilfillan S, Rossini C, Cella M, Barrow AD, Diamond MS, Colonna M: IL-34 is a tissue-restricted ligand of CSF1R required for the development of Langerhans cells and microglia. Nat Immunol 2012, 13:753-760.

29. Turnbull IR, Gilfillan S, Cella M, Aoshi T, Miller M, Piccio L, Hernandez M, Colonna M: Cutting edge: TREM-2 attenuates macrophage activation. J Immunol 2006, 177:3520-3524.

30. Griciuc A, Serrano-Pozo A, Parrado Antonio R, Lesinski Andrea N, Asselin Caroline N, Mullin K, Hooli B, Choi Se H, Hyman Bradley T, Tanzi Rudolph E: Alzheimer's Disease Risk Gene CD33 Inhibits Microglial Uptake of Amyloid Beta. Neuron 2013, 78:631-643.

31. Bertram L, Lange C, Mullin K, Parkinson M, Hsiao M, Hogan MF, Schjeide BMM, Hooli B, DiVito J, lonita I, Jiang H, Laird N, Moscarillo T, Ohlsen KL, Elliott K, Wang X, Hu-Lince D, Ryder M, Murphy A, Wagner SL, Blacker D, Becker KD, Tanzi RE: Genome-wide association analysis reveals putative Alzheimer's disease susceptibility loci in addition to APOE. Am J Hum Genet 2008, 83:623-632.

32. Hollingworth P, Harold D, Sims R, Gerrish A, Lambert JC, Carrasquillo MM, Abraham R, Hamshere ML, Pahwa JS, Moskvina V, Dowzell K, Jones N, Stretton A, Thomas C, Richards A, Ivanov D, Widdowson C, Chapman J, Lovestone S, Powell J, Proitsi P, Lupton MK, Brayne C, Rubinsztein DC, Gill M, Lawlor B, Lynch A, Brown KS, Passmore PA, Craig D, et al: Common variants at ABCA7, MS4A6A/MS4A4E, EPHA1, CD33 and CD2AP are associated with Alzheimer's disease. Nat Genet 2011, 43:429-435.

33. Naj AC, Jun G, Beecham GW, Wang LS, Vardarajan BN, Buros J, Gallins PJ, Buxbaum JD, Jarvik GP, Crane PK, Larson EB, Bird TD, Boeve BF, Graff-Radford NR, De Jager PL, Evans D, Schneider JA, Carrasquillo MM, Ertekin-Taner N, Younkin SG, Cruchaga C, Kauwe JS, Nowotny P, Kramer P, Hardy J, Huentelman MJ, Myers AJ, Barmada MM, Demirci FY, Baldwin CT, et al: Common variants at MS4A4/MS4A6E, CD2AP, CD33 and EPHA1 are associated with late-onset Alzheimer's disease. Nat Genet 2011, 43:436-441.

34. Bradshaw EM, Chibnik LB, Keenan BT, Ottoboni L, Raj T, Tang A, Rosenkrantz LL, Imboywa S, Lee M, Von Korff A, Alzheimer Disease Neuroimaging I, Morris MC, Evans DA, Johnson K, Sperling RA, Schneider JA, Bennett DA, De Jager PL: CD33 Alzheimer's disease locus: altered monocyte function and amyloid biology. Nat Neurosci 2013, 16:848-850.

35. Grathwohl SA, Kalin RE, Bolmont T, Prokop S, Winkelmann G, Kaeser SA, Odenthal J, Radde R, Eldh T, Gandy S, Aguzzi A, Staufenbiel M, Mathews PM, Wolburg H, Heppner FL, Jucker M: Formation and maintenance of Alzheimer's disease beta-amyloid plaques in the absence of microglia. Nat Neurosci 2009, 12:1361-1363.

36. Cady J, Koval ED, Benitez BA, Zaidman C, Jockel-Balsarotti J, Allred P, Baloh RH, Ravits J, Simpson E, Appel SH, Pestronk A, Goate AM, Miller TM, Cruchaga C, Harms MB: TREM2 variant p.r47h as a risk factor for sporadic amyotrophic lateral sclerosis. JAMA Neurology 2014, 71:449-453.

37. Rayaprolu S, Mullen B, Baker M, Lynch T, Finger E, Seeley W, Hatanpaa K, Lomen-Hoerth C, Kertesz A, Bigio E, Lippa C, Josephs KA, Knopman DS White CL 3rd, Caselli R, Mackenzie IR, Miller BL, Boczarska-Jedynak M, Opala G, Krygowska-Wajs A, Barcikowska M, Younkin SG, Petersen RC, Ertekin-Taner N, Uitti RJ, Meschia JF, Boylan KB, Boeve BF, Graff-Radford NR, Wszolek ZK, et al: TREM2 in neurodegeneration: evidence for association of the $p$. $\mathrm{R} 47 \mathrm{H}$ variant with frontotemporal dementia and Parkinson's disease. Mol Neurodegeneration 2013, 8:19.

doi:10.1186/1750-1326-9-20

Cite this article as: Ulrich et al:: Altered microglial response to $A \beta$ plaques in APPPS1-21 mice heterozygous for TREM2. Molecular Neurodegeneration 2014 9:20. 